\title{
Effect of the Welding Parameters on the Structural and Mechanical Properties of Aluminium and Copper Sheet Joints by Electromagnetic Pulse Welding
}

\author{
Irene Kwee ${ }^{1 *}$, Verena Psyk ${ }^{2}$, Koen Faes ${ }^{1}$ \\ ${ }^{1}$ Belgian Welding Institute, Zwijnaarde, Belgium \\ ${ }^{2}$ Fraunhofer Institute for Machine Tools and Forming Technology, Fraunhofer Institute, Chemnitz, Germany \\ Email: *irene.kwee@bil-ibs.be
}

How to cite this paper: Kwee, I., Psyk, V. and Faes, K. (2016) Effect of the Welding Parameters on the Structural and Mechanical Properties of Aluminium and Copper Sheet Joints by Electromagnetic Pulse Welding. World Journal of Engineering and Technology, 4, 538-561.

http://dx.doi.org/10.4236/wjet.2016.44053

Received: August 23, 2016

Accepted: November 6, 2016

Published: November 9, 2016

Copyright $\odot 2016$ by authors and Scientific Research Publishing Inc. This work is licensed under the Creative Commons Attribution International License (CC BY 4.0).

http://creativecommons.org/licenses/by/4.0/

\begin{abstract}
Aluminium-copper hybrid parts, as a substitution to copper parts, result in weight and cost reduction, and are relevant in applications related to the electronic, heating and cooling sector. However, aluminium to copper joined by thermal welding processes presents challenges in terms of achieving good joint quality. This is attributed to their dissimilar mechanical and thermal properties which result in large stress gradients during heating. This study investigated joining of aluminium to copper sheets by electromagnetic pulse welding, which is a solid-state process that uses electromagnetic forces for joining of dissimilar materials. Hybrid sheet welds were obtained for all parameters conditions, selected according to a Taguchi L18 design. The structural and mechanical characteristics were examined and related to the welding parameters by means of a Pareto analysis and response graphs. The welded zone started with a wavy interface with interfacial layers and defects and evolved to a flat interface without interfacial layers. The maximum transferable force depended on the minimum specimen thickness and the strength of the hybrid sheet weld. In case of aluminium sheet thickness reduction, the maximum transferable force was linearly correlated with the aluminium sheet thickness. High quality joints were obtained for no aluminium sheet thickness reduction and for a sheet weld strength which was at least as high as that of the base material. The most effective way to increase the transferable force was to lower the initial gap and to increase the free length, which resulted in no aluminium sheet thickness reduction. Alternatively, the use of a rounded spacer decreased the effect of the aluminium sheet thickness on the transferable force. An increase in weld width was achieved for an increase in capacitor charging energy and gap, whereas an increase in weld length was obtained for a de-
\end{abstract}


crease in gap. An increase in weld width did not necessarily result in an increase in the transferable force. In the regarded cases, a hybrid sheet with narrow weld width could therefore have higher quality.

\section{Keywords}

Electromagnetic Pulse Sheet Welding, Aluminum-to-Copper Welds,

Dissimilar Metal Welds, Transferable Force, Interfacial Morphology

\section{Introduction}

Global trends force industry to manufacture lighter, safer, more environmental friendly, more performant and cheaper products. A multi-material design exploits materials with desired properties for each part of the component or product. However, design of products is hindered by challenges in the field of joining technology. Conventional thermal welding technologies are mostly suitable for assemblies of similar metals with comparable melting temperatures, and hence restrict the materials that can be joined, the type and the quality of the joint. In contrast, solid-state welding technologies allow both dissimilar and similar metals to be joined, since no significant melting of the base metals occurs.

Electromagnetic pulse welding is an innovative solid-state welding technology that belongs to the group of pressure welding processes, since it uses electromagnetic forces for the deformation and joining of materials. It was originally suggested in [1]. Electromagnetic pulse welding is based on the electromagnetic forming process, which was invented by Harvey and Brower in the 1960s [2]. In this process, a power supply is used to charge a capacitor bank. When the required amount of energy is stored in the capacitors, it is instantaneously released into a coil, during a very short period of time (typically $10-15 \mu \mathrm{s}$ ). The discharge current induces a strong transient magnetic field in the coil, which in turn induces eddy currents and a magnetic field in the outer workpiece. The interaction between these two magnetic fields generates a Lorentz force. In case of electromagnetic pulse welding, this force causes one workpiece to impact with another workpiece. Under the correct circumstances, this leads to an atomic bond between the two metal workpieces. The electromagnetic welding mechanism is therefore similar to explosion welding, since the deformation takes places at a very high velocity. The deformation force is however created in a safe way, by using electromagnetic forces instead of explosives [3]. A comprehensive review of the electromagnetic forming process, including a section about electromagnetic pulse welding is given in [4] [5].

Compared to thermal welding processes, important advantages of electromagnetic pulse welding have been documented in literature. One important issue is that pressure instead of heat is employed to realise the metallic bond, as stated by [6]. Numerical simulations considering the temperature development during electromagnetic pulse welding support this theory [7] [8]. An experimental confirmation of the absence of eutectic microstructure via microstructural analysis is given in [9]. However, other 
publications suggest that especially at high capacitor charging energies very locally high temperatures can lead to melting and solidification, which at least contributes to the weld formation [10] [11]. Another advantage includes joining of conventionally nonweldable materials in a quick and cost-effective manner. An example of such a weld is given in [12]. Here aluminium tubes are electromagnetically pulse welded to titanium rods. This material combination is usually very problematic, due to the high affinity of titanium to atmospheric gases at elevated temperatures, which leads to the formation of hard and brittle metalloid phases. Additionally, in electromagnetic pulse welding the negligible temperature increase of the part allows immediately unloading and further processing with other equipment. Moreover, the high repeatability [13] [14], the contact-free process character allowing the use of coated or sensitive materials [15] and the lower environmental impact [16] are benefits of electromagnetic pulse welding.

Dissimilar aluminium-copper joints are of interest for wiring and cable systems, where they are commonly employed in transition pieces for high direct current bus systems. The partial substitution of copper with aluminium allows for both mass and cost reduction, with a minimum loss of conductivity. In the field of e-mobility, aluminium-copper joints are used to connect additional cells to batteries consisting of aluminium and copper electrodes [17] [18].

However, the hybrid structure of aluminium to copper presents a number of challenges in terms of achieving a high strength joint. Both copper and aluminium have some similar properties that make it difficult to weld by fusion welding. These include high thermal conductivity, high thermal expansion coefficient, relatively low melting point, brittleness at elevated temperatures and less viscosity of molten metals. Moreover, aluminium to copper joined by fusion welding can contain large stress gradients, due to their highly dissimilar mechanical properties and different thermal expansion coefficients [17] [19]. Also the resulting melting pool and subsequent formation of brittle intermetallic phases, can lead to cracking of the joint during cooling down. On the other hand, solid-state welding techniques such as electromagnetic pulse welding allow for joining to occur below the melting temperature [17].

Electromagnetic pulse welding can be used for tubular and sheet applications, placed in the overlap configuration. Mainly aluminium-copper tubular components have been documented in literature for their interfacial morphology and mechanical properties [19] [20] [21]. In contrast, research on the interfacial morphology and mechanical characteristics of aluminium to copper sheet components is rather limited [22]-[24]. This is attributed to difficulties in concentrating and controlling the magnetic field in the flat coil [25] [26]. Also the effect of the process parameters on aluminium to copper sheet joints has not been studied so far.

The objective of the present work was to investigate the electromagnetic pulse welding of aluminium to copper sheets achieved at different parameter combinations. These were selected according to a Taguchi L18 design. First, the weld shape, interfacial morphology, transferable force, failure modes and dimensions of the weld seam were analysed in detail. Subsequently, the effect of the welding parameters on these structural 
and mechanical characteristics was investigated using a statistical approach. Finally, a modification of the experimental set-up is examined to improve the maximum transferable force of the hybrid sheet weld.

\section{Experimental Procedure}

\subsection{Material Details}

ENAW-1050 H14 and Cu-DHP R240 (Phosphorus-Deoxidised Copper) sheet materials were used for the present study. Both sheets have a width of $240 \mathrm{~mm}$ and a thickness of $1 \mathrm{~mm}$. Their mechanical characteristics are shown in Table 1.

\subsection{Electromagnetic Pulse Welding Equipment}

The electromagnetic pulse welding installation comprises 4 main parts, as shown in Figure 1(a).

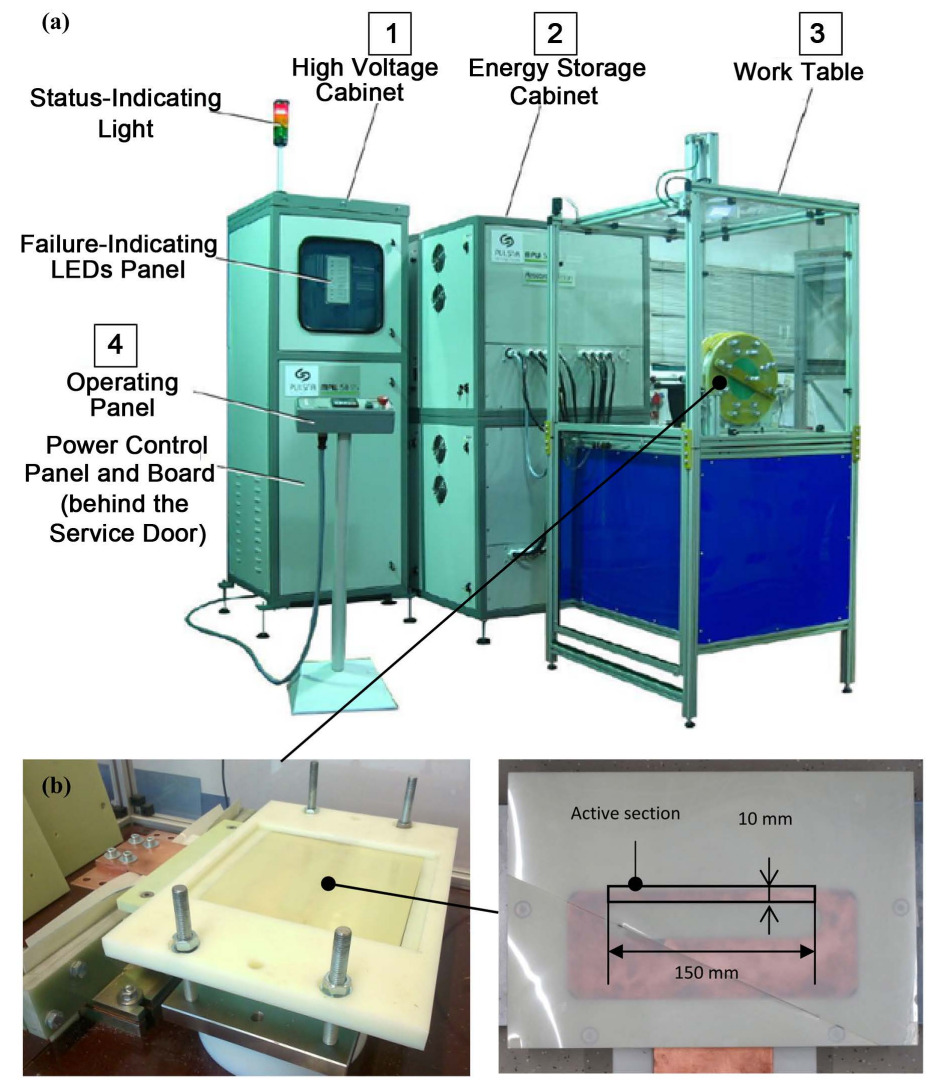

Figure 1. (a) Electromagnetic pulse welding installation; (b) tool coil applied for sheet welding.

Table 1. Properties of the EN AW-1050 H14 [27] and Cu-DHP R240 sheet [28].

\begin{tabular}{ccccc}
\hline Sheet material & $\begin{array}{c}\text { Hardness } \\
{[\mathrm{HV}]}\end{array}$ & $\begin{array}{c}\text { Yield strength }\left(\mathrm{R}_{\mathrm{p} 0.2}\right) \\
{[\mathrm{MPa}]}\end{array}$ & $\begin{array}{c}\text { Tensile strength }\left(\mathrm{R}_{\mathrm{m}}\right) \\
{[\mathrm{MPa}]}\end{array}$ & $\begin{array}{c}\text { Elongation }\left(\boldsymbol{A}_{50 \mathrm{~mm}}\right) \\
{[\%]}\end{array}$ \\
\hline EN AW-1050 H14 & 30 & $\geq 85$ & $105-145$ & $\geq 2$ \\
Cu-DHP R240 & $65-95$ & $\geq 180$ & $240-300$ & $\geq 8$ \\
\hline
\end{tabular}


1) High-voltage cabinet containing the grid power supply, which is used to charge the capacitor bank,

2) Energy storage bank containing the capacitors, which stores the energy that is used to accelerate the sheet,

3) Work table containing the coil, which generates the magnetic field necessary for accelerating the sheet and producing the weld,

4) Control panel, for setting the required voltage.

The main characteristics of the pulsed power generator (Pulsar MPW 50/25) are summarized in Table 2.

The tool coil used for all tests is illustrated in Figure 1(b). This rectangular coil was manufactured by Poynting GmbH, Dortmund [29]. It has an active section of the winding, which is used for welding, while other parts of the winding serve for closing the current loop only. The width and length of the active section of the conductor are $10 \mathrm{~mm}$ and $150 \mathrm{~mm}$, respectively.

\subsection{Experimental Set-Up Configuration and Electromagnetic Pulse Welding Principle}

Figure 2 presents a cross-sectional view of the active section of the coil conductor depicted in Figure 1(b). It shows the configuration of the aluminium and copper sheet in relation to the tool coil. The aluminium sheet is called flyer sheet and is located on top of the coil conductor. The copper sheet is called target sheet. The gap is the distance by

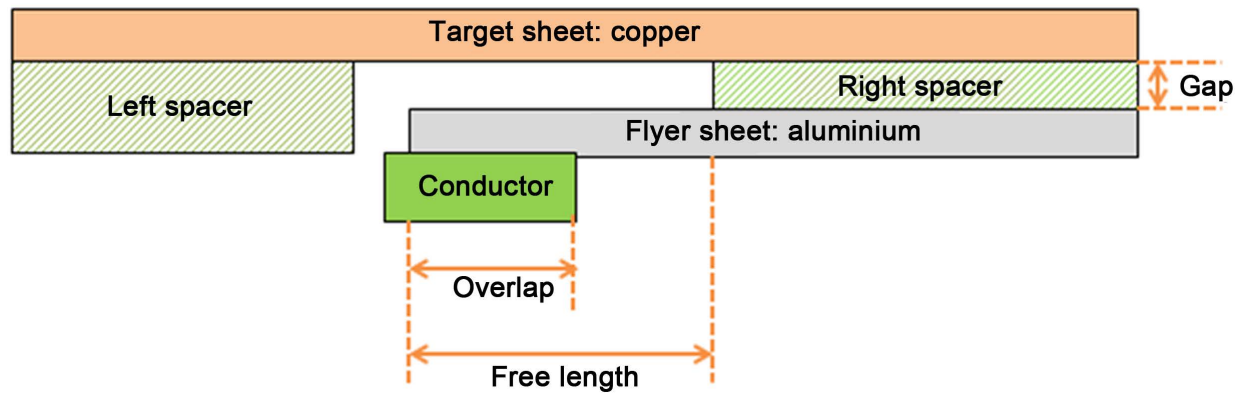

Figure 2. Principle set-up configuration with a straight, sharp-edged spacer, used for all the parameter combinations. Cross-sectional view of the active section of the coil conductor in Figure 1 (b).

Table 2. Characteristics of the pulsed power generator (Pulsar MPW 50/25).

\begin{tabular}{cc}
\hline Characteristic & Value \\
\hline Maximal charging voltage & $25 \mathrm{kV}$ \\
Maximal storage energy & $50 \mathrm{~kJ}$ \\
Maximal pulse energy & $40 \mathrm{~kJ}(22.36 \mathrm{kV})$ \\
Maximal pulse current & $500 \mathrm{kA}$ \\
Voltage-energy ratio & $V=\sqrt{\frac{E}{80}}$, where E in $[\mathrm{J}]$ and $\mathrm{V}$ in $[\mathrm{kV}]$
\end{tabular}


which the aluminium flyer sheet is separated from the copper target sheet prior to discharge. The overlap is the overlap distance between the tool coil and the aluminium flyer sheet. The free length is the part of the aluminium flyer sheet that is being accelerated towards the copper target sheet. Figure 2 illustrates the principle set-up configuration that employs a straight, sharp-edged spacer and is used for all parameter combinations. The function of this spacer is to create the gap between the aluminium flyer and copper target sheet. A modified set-up configuration is depicted in Figure 3. This one uses a rounded right spacer, which is only applied for a selection of parameter combinations.

The electromagnetic welding principle is as follows: in first instance, an AC current in the power supply is rectified which charges the capacitor bank to the selected energy level. The electrical energy stored in the capacitors is the discharge energy. Once the bank is charged, the switch is closed and the energy is instantaneously discharged through the coil. A damped sinusoidal current induces a strong transient magnetic field in the coil. The magnetic flux lines intersect with the aluminium flyer sheet, which results in an induced electromagnetic force and corresponding Eddy currents and magnetic field. This magnetic field caused by the Eddy currents in the aluminium flyer sheet opposes the original transient magnetic field caused by the coil current. The difference in magnitude of the magnetic fields generates Lorentz' forces that repel the aluminium flyer sheet away from the coil. Hence, the aluminium sheet impacts with the copper target sheet at high velocity in a few microseconds. If collision angle and velocity are in the range of the weldability window, a jetting effect occurs which causes the expulsion of oxides and contaminations on both sheet surfaces. After collision, the resulting Lorentz forces press the atomically clean surface of the aluminium flyer and copper target sheet together to form a weld. Bonding between the two materials occurs when the distance between their atoms becomes smaller than the range of their mutual attractive forces [21] [25].

\subsection{Parameter Combinations}

Based on exploratory welding experiments, a set of parameters was identified that produced a sound weld. However, 54 parameter combinations would have to be considered

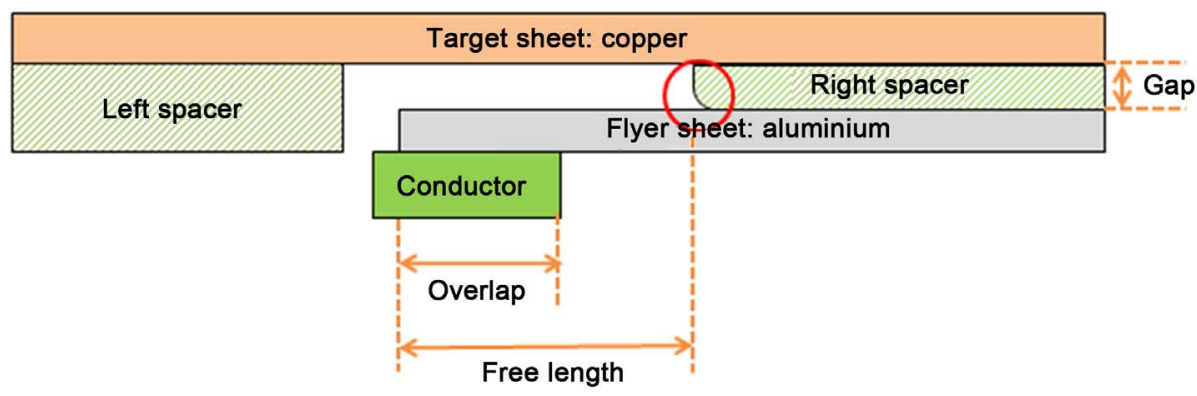

Figure 3. Modified set-up configuration with a rounded spacer, used for a selection of the parameter combinations. Cross-sectional view of the active section of the coil conductor in Figure 1 (b). 
in order to perform a full factorial research. Other statistical methods were therefore employed for the design of experiments and the interpretation of the results. This allowed reducing the number of experiments without losing a significant amount of information and accuracy. For this purpose, the Taguchi design L18 was applied, for which only 18 out of the 54 parameter combinations were selected. The according parameter combinations are listed in Table 3.

The following welding parameters were varied, namely:

- Capacitor charging energy $E$,

- Overlap between flyer sheet and actuator $o$,

- Initial gap between flyer and target $g_{\text {initial }}$,

- Free length $l$.

The fixed parameters were chosen as:

- Capacitance $C=160 \mu \mathrm{F}$,

- Target thickness $t_{\text {target }}=$ Flyer thickness $t_{\text {flyer }}=1 \mathrm{~mm}$,

- Target width $w_{\text {target }}=$ Flyer width $w_{\text {flyer }}=240 \mathrm{~mm}$,

- Active length and width of tool coil $=150$ and $10 \mathrm{~mm}$.

Table 3. Parameter combinations, based on the Taguchi L18 design, considered for analysing electromagnetic sheet welding of EN AW1050 flyers to Cu-DHP R240 targets.

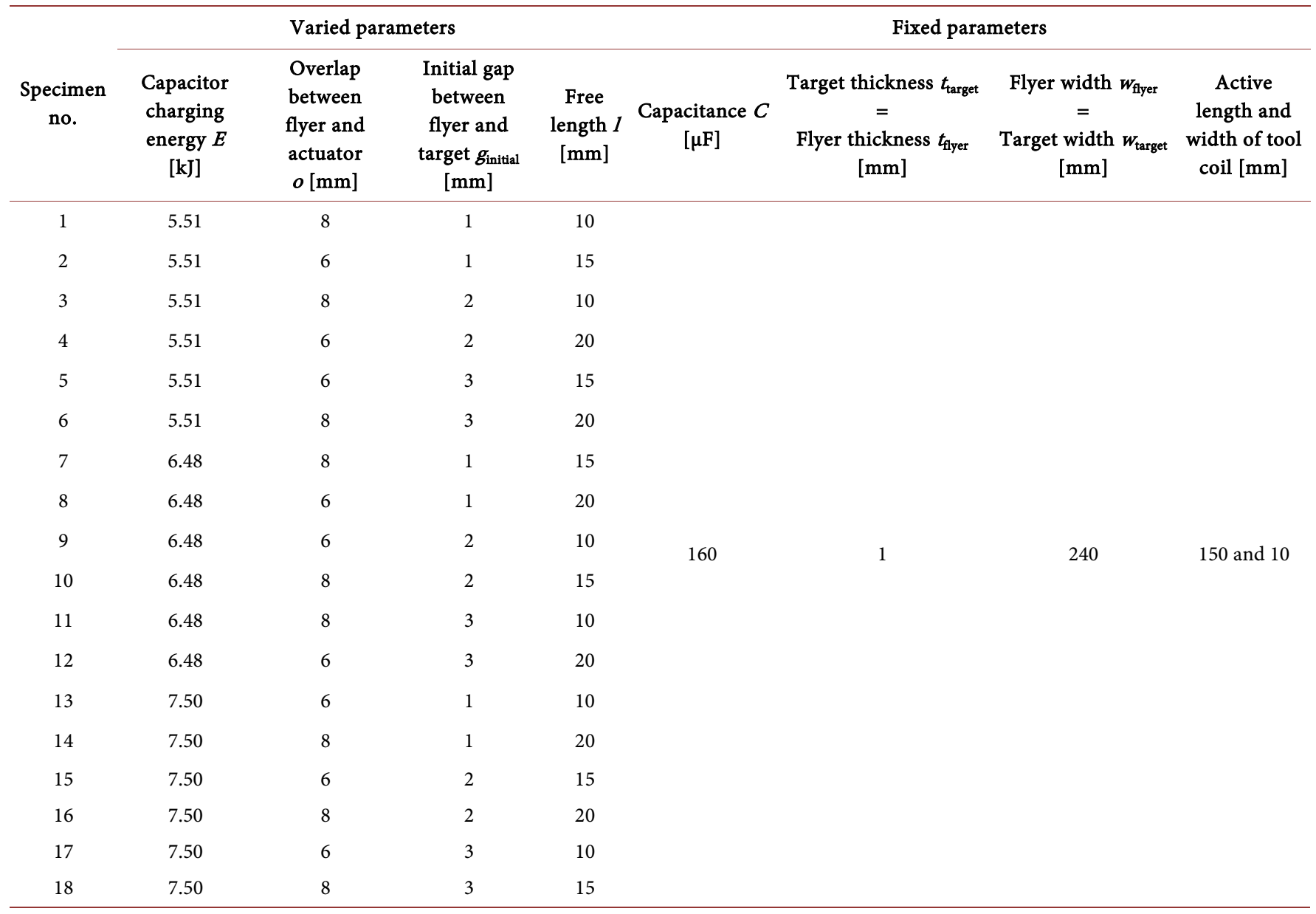


All parameter combinations were performed according to the principle set-up configuration shown in Figure 2. The experiments were carried out in a random order, in order to minimise the risk of consecutive errors and to reduce the possible influence of nuisance variables (such as temperature and humidity) that are not controlled in the experimental design.

Prior to conducting a welding experiment, the flyer sheet and target sheet dimensions were measured to ensure the correct geometrical parameters. Subsequently, both parts were cleaned thoroughly using steel wool and acetone. This removed all contaminations from the surfaces, such as dust particles or lubricating oil from the machining process. Otherwise, these contaminations could possibly interfere with the creation of a welded joint. In [30], it is stated that the surface of the part should be as clean as possible. In that case, already at relatively low charging energy the jet effect is sufficient to clean the surface from the remaining contamination. Consequently weld formation is fostered.

\section{Weld Characterisation}

The weld quality was first determined by visual inspection of the weld shape and quantification of the length of the weld seam. Furthermore, metallographic examination was conducted to quantify the width of the weld seam and to investigate the interfacial morphology. Lap shear testing was performed to obtain the maximum transferable force. To that end, the hybrid sheet weld was cross sectioned perpendicular to the weld seam. In this way, 1 specimen (dimensions $5 \times 30 \mathrm{~mm}$ ) for metallographic examination and 3 specimens for lap shear testing (dimensions $45 \times 270 \mathrm{~mm}$ ) was obtained (see Figure 4). The metallography specimen was embedded in epoxy, grinded and mechanically polished to obtain metallographic cross-sections for optical microscopy.

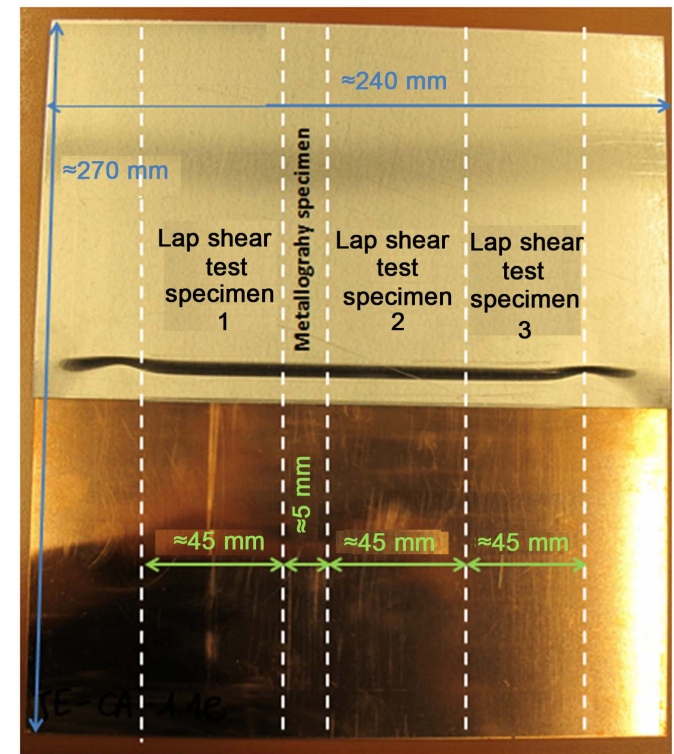

Figure 4. As-welded EN AW-1050/Cu-DHP R240 sheet weld, cross-sectioned perpendicular to the weld seam to obtain 1 metallography specimen and 3 lap shear test specimens. 
Furthermore, the load course during magnetic pulse welding was characterised via measuring the inductor current. This was done with the aid of a Rogowski coil during all experiments. The following significant characteristics were determined from the current courses (see also Figure 5):

- Significant frequency $f$, according to [31], which can be calculated based on the current rise time $t_{\text {rise }}$ according to Equation (1)

- Maximum inductor current $I_{\max }$

$$
f=\frac{1}{4 \cdot \Delta t_{\text {rise }}} .
$$

It turned out that the significant frequency varied between 42.7 and $48.5 \mathrm{kHz}$ for all considered parameter combinations. Thus, none of the regarded varied parameters had a noteworthy effect on the frequency. The maximum inductor current varied between 229 and $301 \mathrm{kA}$.

Figure 5 shows a typical current course during magnetic pulse welding, for which the first half wave of the current course is relevant since welding occurs within this time period.

\section{Results and Discussion}

\subsection{As-Welded Hybrid Sheet Weld: Weld Shape and Weld Length}

Aluminium/copper sheet welds were successfully obtained for all parameters conditions considered. A typical example of such a hybrid sheet weld is shown in Figure 6(a). The weld length, i.e. the extension of the weld seam parallel to the coil conductor, was measured based upon visual inspection. The range of weld lengths achieved for

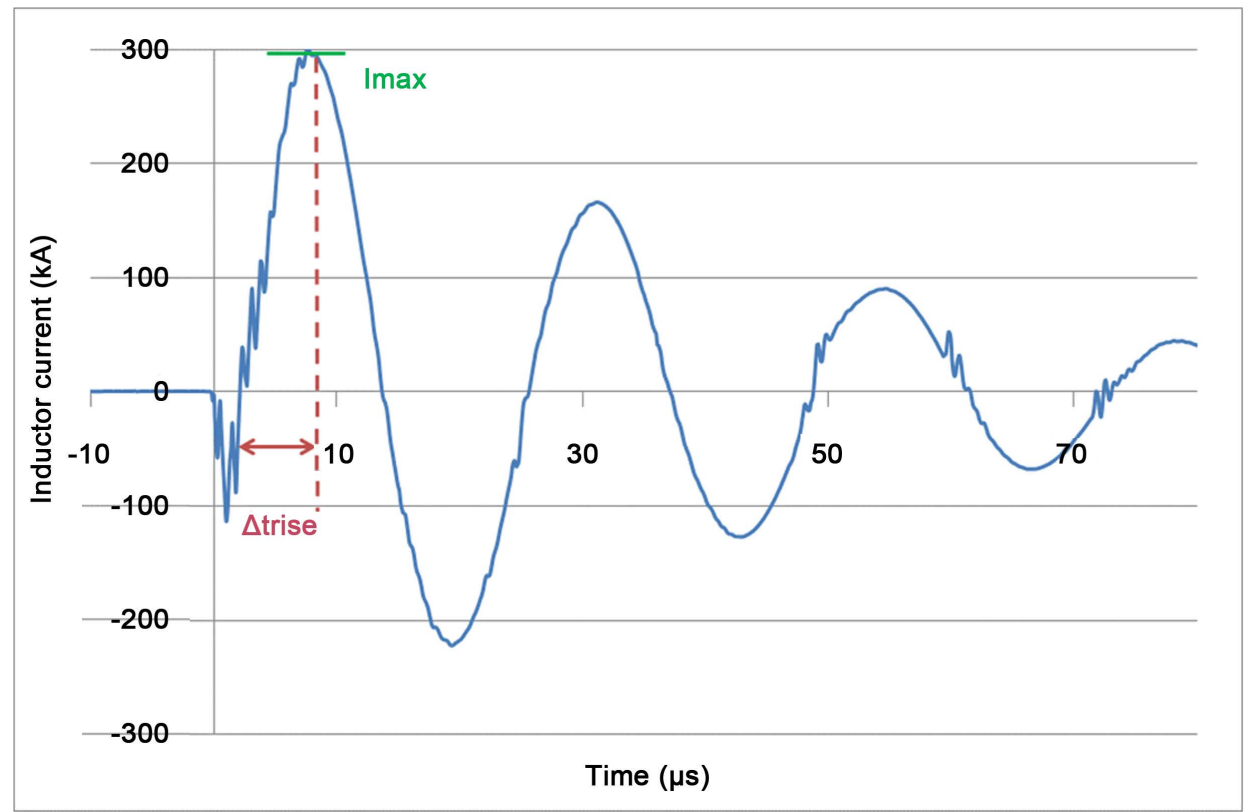

Figure 5. Typical current course during magnetic pulse welding of EN AW-1050 flyer to CuDHP R240 target (specimen no. 14). 


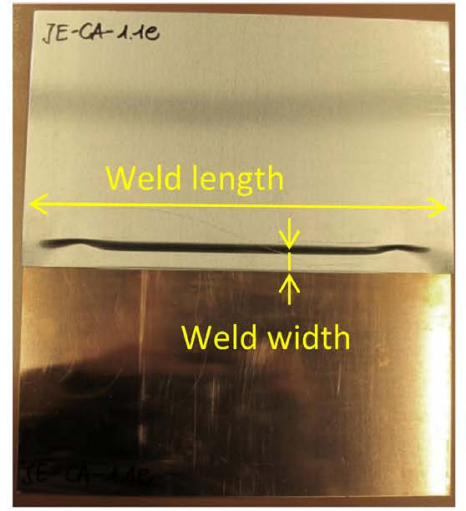

(a)

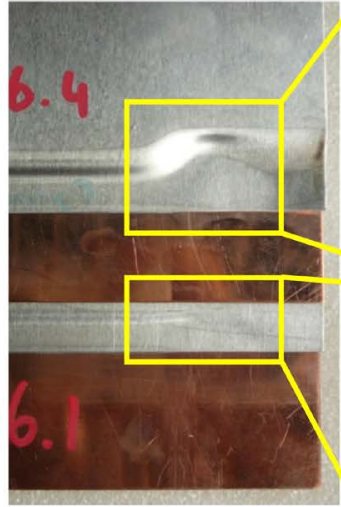

(b)

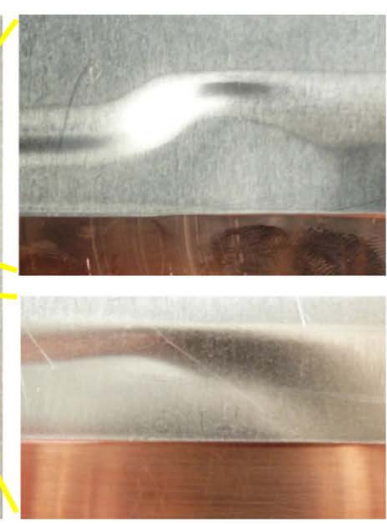

Figure 6. (a) EN AW-1050/Cu-DHP R240 sheet weld with an indication of the length and width of the weld seam, (b) Indent shape located at the extremities of the hybrid sheet weld.

all parameter combinations varied from 165 to $182 \mathrm{~mm}$, which corresponded to approximately $69 \%-76 \%$ welded length of the total sheet length. A summary of the weld lengths obtained is listed in Table 4. The weld width-i.e. the extension of the weld seam-was quantified based upon metallographic examination. This will be discussed in section 4.2.

Visual examination showed that an indent shape located at the extremities of the weld was present, as indicated in Figure 6(b). This indent was attributed to the change of the current direction at the end of the coil conductor, which resulted in a current concentration at the sheet extremities. In addition, a reduction in the aluminium sheet thickness near the welded zone was observed. No rupture of the aluminium sheet however was detected.

\subsection{Weld Interface: Interfacial Morphology and Weld Width}

A typical metallographic cross-section obtained at the centre of the hybrid sheet weld is illustrated in Figure 7(a). The first impact was at the left extremity of the aluminium flyer sheet, after which the welding formation advanced to the right. In general, all metallographic cross-sections showed that the welded sheets evolved from a non-welded zone to a welded zone. This can possibly be attributed to the evolution of the direction and magnitude of the Lorentz force. This force determines the impact angle and the impact velocity during the welding process, as illustrated by measurements and modelling studies performed by [12] [24] [32] [33]. The combination of the impact angle and the impact velocity is defined in the so-called welding window, which specifies the requirements of the impact angle and impact velocity for welding to occur [32]. [34] exemplary shows the course of impacting angle and velocity during alignment of flyer and target in relation to the welding window. It specifically shows that the curve describing this course of collision parameters can leave and re-enter the welding window, leading to unwelded zones in the part. The welded zone corresponds to the width of the weld seam. In addition, a reduction of the aluminium sheet thickness near the welded zone was observed in some specimens. 


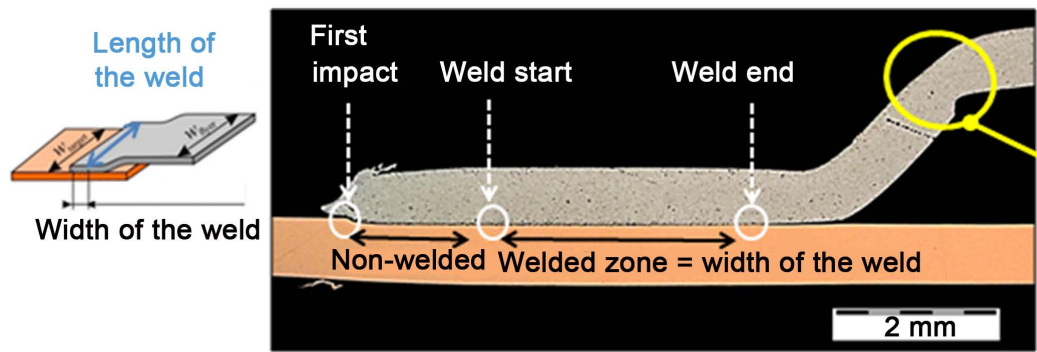

Aluminium

sheet

thickness

reduction

(a)

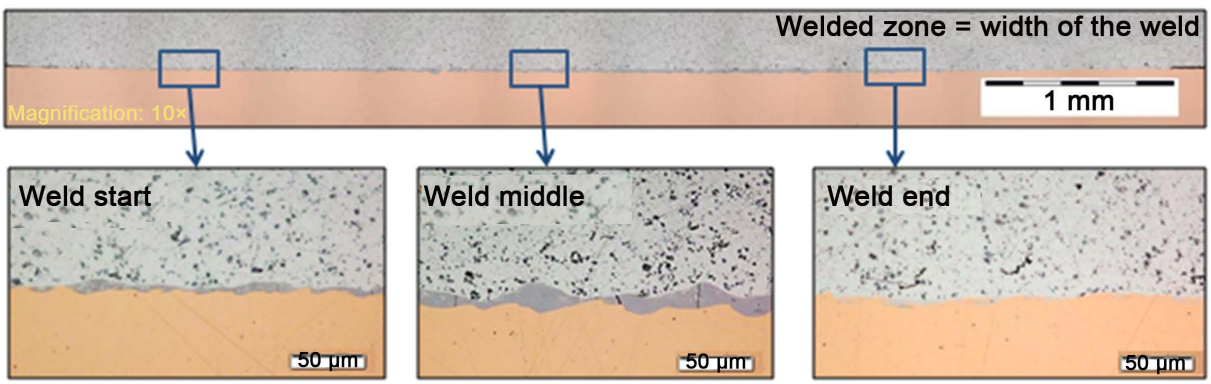

(b)

Figure 7. (a) Typical metallographic cross section, obtained at the centre of the hybrid sheet weld; (b) Detailed view of the interfacial morphology evolution (specimen no. 2).

A detailed view of a typical interfacial morphology evolution of a welded zone is presented in Figure 7(b). At first, the welded zone started with a relatively flat interface with a small light grey interfacial layer. Subsequently in the weld middle, the interface waviness amplitude-defined as the difference between the maximum and the minimum of a wave-increased. Also the interfacial layer thickness increased as well (indicated in Figure 8). The composition of the interfacial layer evolved to a mixture of light grey and dark grey layers, which denoted that different phases were present within the layer. Moreover the interfacial layer became strongly porous, with randomly dispersed porosities in different sizes. These porosities could originate from either melting or metallographic preparations. The transverse microcracks in the interfacial layer can result from shear stresses, developed during solidification cracking. These shear stresses could arise because of differences in the thermal expansion coefficient of the adjacent copper and aluminium, as investigated by [20]. Finally towards the weld end, a small wavy interface and thin interfacial layer without any defects was present. In general, the interfacial waviness amplitude and interfacial layer thickness observed for all parameter combinations ranged from 4 to $12 \mu \mathrm{m}$ and from 2 to $14 \mu \mathrm{m}$, respectively.

The width of the weld seam was quantified, based on measurements on the metallographic cross-sectional views as shown in Figure 7(b). These weld widths ranged from 1 to $6 \mathrm{~mm}$ and are summarised in Table 4 . The effect of the welding parameters on the width and the length of the weld seam will be discussed in the Section 4.4.

\subsection{Transferable Force and Failure Mode}

Lap shear testing was conducted in order to obtain the maximum transferable force of 
Table 4. Quantification of the weld seam, measurement of the aluminium sheet thickness reduction and results of the lap shear test.

\begin{tabular}{|c|c|c|c|c|c|c|}
\hline \multirow[b]{2}{*}{$\begin{array}{c}\text { Specimen } \\
\text { no. }\end{array}$} & \multirow{2}{*}{$\begin{array}{c}\text { Visual } \\
\text { inspection } \\
\\
\text { Length } \\
\text { of the weld } \\
\text { seam } \\
\text { [mm] }\end{array}$} & \multicolumn{2}{|c|}{ Metallographic analysis } & \multicolumn{3}{|c|}{ Lap shear test } \\
\hline & & $\begin{array}{l}\text { Width } \\
\text { of the weld } \\
\text { seam }\end{array}$ & $\begin{array}{l}\text { Aluminium sheet } \\
\text { thickness after } \\
\text { welding [mm] }\end{array}$ & Failure position & $\begin{array}{l}\text { Absolute value of } \\
\text { the maximum } \\
\text { transferable force in } \\
\text { the lap shear test }[\mathrm{kN}]\end{array}$ & $\begin{array}{c}\text { Maximum } \\
\text { transferable } \\
\text { force/specimen } \\
\text { width }[\mathrm{N} / \mathrm{mm}]\end{array}$ \\
\hline 1 & 173.4 & 1.1 & 0.9 & In the joint & 4.6 & 102.2 \\
\hline 2 & 174.8 & 3.3 & 1.0 & In the aluminium base material & 5.3 & 117.8 \\
\hline 3 & 168.5 & 4.8 & 0.8 & In the aluminium base material & 4.4 & 97.8 \\
\hline 7 & 175.9 & 1.4 & 1.0 & In the joint & 5.1 & 113.3 \\
\hline 8 & 176.6 & 4.0 & 1.0 & In the aluminium base material & 5.3 & 117.8 \\
\hline 9 & 172.6 & 3.8 & 0.8 & In the aluminium base material & 4.7 & 104.4 \\
\hline 10 & 171.2 & 5.9 & 0.7 & In the aluminium base material & 4.2 & 93.3 \\
\hline 11 & 167.9 & 4.9 & 0.5 & In the aluminium base material & 2.6 & 57.8 \\
\hline 12 & 168.9 & 3.2 & 1.0 & In the aluminium base material & 5.2 & 115.6 \\
\hline 13 & 177.8 & 4.2 & 0.9 & In the aluminium base material & 5.2 & 115.6 \\
\hline 18 & 171.8 & 5.0 & 1.0 & In the aluminium base material & 5.1 & 113.3 \\
\hline
\end{tabular}

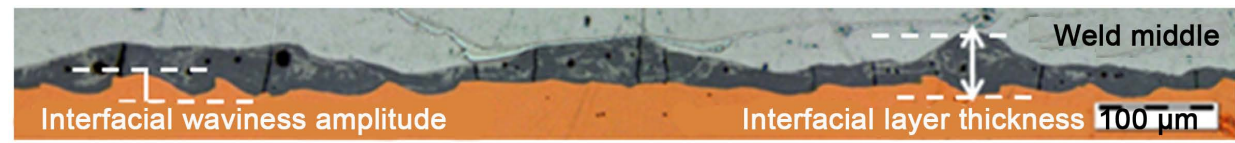

Figure 8. Detail of the interfacial layer morphology in the weld middle and indication of the interfacial waviness amplitude and interfacial layer thickness.

the hybrid sheet weld. The dimensions of the lap shear test specimen were $45 \times 270 \mathrm{~mm}$ (see Figure 9). Three lap shear tests were carried out for each parameter combination in order to guarantee reproducibility of the results. The absolute values of the maximum transferable force ranged from 2.6 to $5.3 \mathrm{kN}$. Accordingly the maximum transferable force/specimen width ranged from 57.8 to $115.6 \mathrm{kN}$. These results are listed in Table 4. Two different general failure modes-failure in the base material and failure in the joint-occurred during lap shear testing. Most of the specimens failed in the 


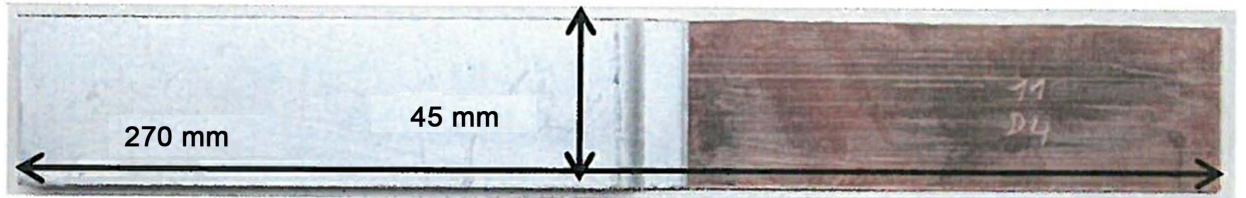

Figure 9. Geometry of the lap shear test specimen.

aluminium base material due to necking, either close to the joint or further away from the joint. In contrast, failure in the joint occurred in very few cases only.

Figure 10 illustrates the type of failure mode and the corresponding transferable force/specimen width versus elongation graphs for the hybrid sheet weld. These graphs were compared to the transferable force/specimen width of the aluminium base material. The width of the lap shear test specimen was $45 \mathrm{~mm}$, whereas the width of the tensile test specimen was $20 \mathrm{~mm}$.

For hybrid sheet welds with no aluminium thickness sheet reduction after welding, Figure 10(a) shows that the transferable force/specimen width of the hybrid sheet weld reached that of the base material. Accordingly, the strength of the hybrid sheet weld was at least as high as that of the base material. This behaviour was defined as a "high quality" joint. In this case, the hybrid sheet weld typically failed in the base material. For hybrid sheet welds with an aluminium sheet thickness reduction of approximately $50 \%$, Figure 10(b) illustrates that the transferable force/specimen width of the hybrid sheet weld was slightly more than $50 \%$ of that of the base material. This can be explained since the transferable force/specimen width depends on the minimum specimen thickness (which is about $50 \%$ of that of the base material here) and the strength of the hybrid sheet weld. This strength might be slightly increased in the hybrid sheet weld, due to strain hardening effects during electromagnetic pulse welding. Regarding joint quality evaluation, it can be stated that the strength of the hybrid sheet weld exceeded $50 \%$ of that of the base material, but it cannot be known whether or not it reached the strength of the base material. Also in this case, failure typically occurred in the base material, due to the large sheet thickness reduction. For hybrid sheet welds with an aluminium sheet thickness reduction of approximately 10\%, Figure 10(c) shows that the transferable force/width of the hybrid sheet weld was slightly lower compared to that of the base material. Accordingly, the strength of the sheet weld was slightly lower compared to that of the base material. This is also the reason why the specimen failed in joint and not in the base material, here.

Also, the maximum transferable force obtained was linearly correlated to the aluminium sheet thickness after the welding operation (see Table 4): a reduced aluminium sheet thickness resulted in a lower maximum transferable force. For failure in the aluminium base material, a high maximum transferable force of $5.3 \mathrm{kN}$ (specimen no. 2) was achieved when no reduction of the aluminium sheet thickness after welding has occurred. However, a much lower transferable force of $2.6 \mathrm{kN}$ (specimen no. 11) was obtained at 50\% reduction of the aluminium sheet thickness. This is also the highest $\%$ sheet thickness reduction found for all failures in the aluminium base material. Like 
Type 1: Failure in the aluminium base material

Close to the joint or Further away from the joint
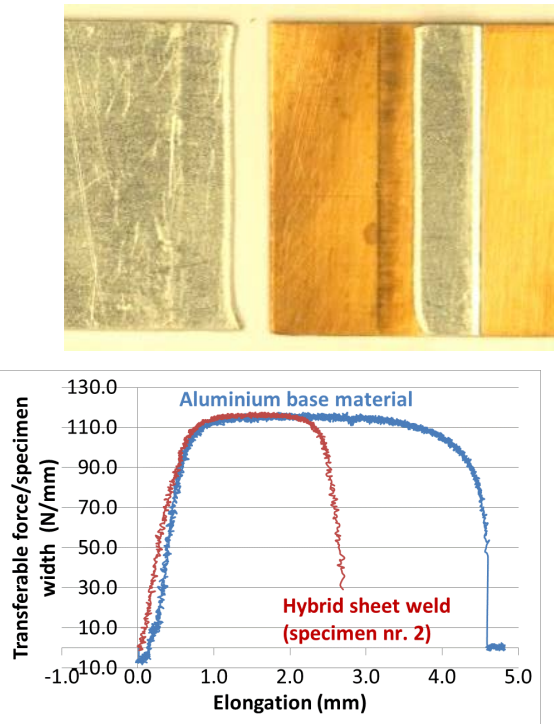

(a)
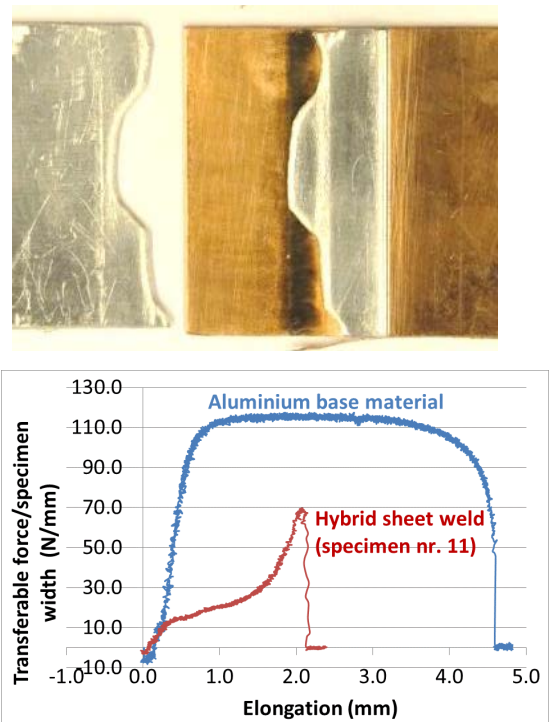

(b)
Type 2: Failure in the joint
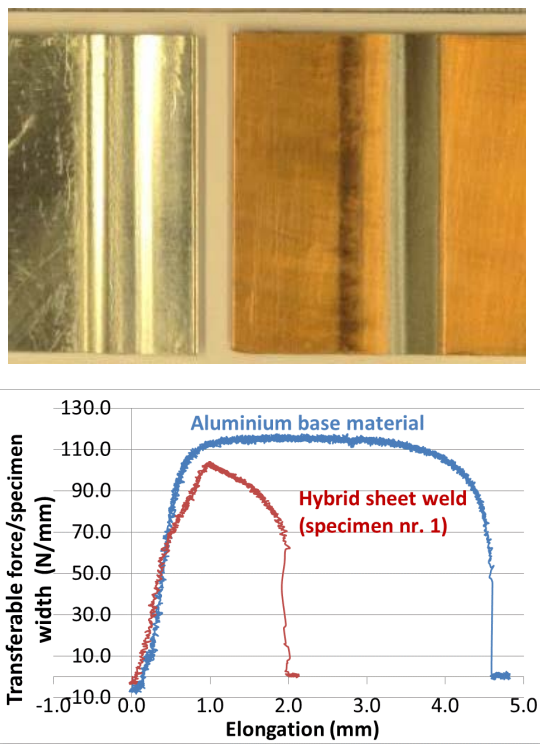

(c)

Figure 10. Two types of failure cases and corresponding transferable force/specimen width vs. elongation curves for hybrid sheet welds of aluminium flyers to copper targets (width of the lap shear test specimen $=45 \mathrm{~mm}$, width of the tensile test specimen $=20 \mathrm{~mm}$ ). (a) No aluminium sheet thickness reduction; (b) With $50 \%$ aluminium sheet thickness reduction (=max. reduction observed for failure in the aluminium base material); (c) With $10 \%$ aluminium sheet thickness reduction (=max. reduction observed for failure in the joint).

wise, for failure in the joint, a transferable force of 5.1 and $4.6 \mathrm{kN}$ was achieved at no aluminium thickness reduction and at a $10 \%$ aluminium thickness reduction, respectively. The highest \% reduction of the aluminium sheet thickness was therefore observed for failure in the aluminium base material. This correlation between the maximum transferable force and the aluminium sheet thickness reduction will be discussed in more detail in Section 4.4. In this section, the welding parameters are related to the maximum transferable force.

Moreover, the occurrence of the 2 types of failure modes is related to the measured weld width (see Table 4). Failure in the joint only occurred at smaller weld widths, ranging from 1.1 to $1.4 \mathrm{~mm}$. In contrast, failure in the aluminium base material only occurred for longer welder widths, ranging from 2.3 to $6.1 \mathrm{~mm}$. However, no correlation between the maximum transferable force and the weld width nor the weld length was identified.

\subsection{Effect of Welding Parameters on the Structural and Mechanical Characteristics}

The relation between the various welding parameters and the aluminium thickness sheet reduction after welding, the maximum transferable force and the dimensions of the weld seam was thoroughly investigated. To this end, the individual results of the 18 different parameter combinations (orange dots in Figure 11 and following) were first 


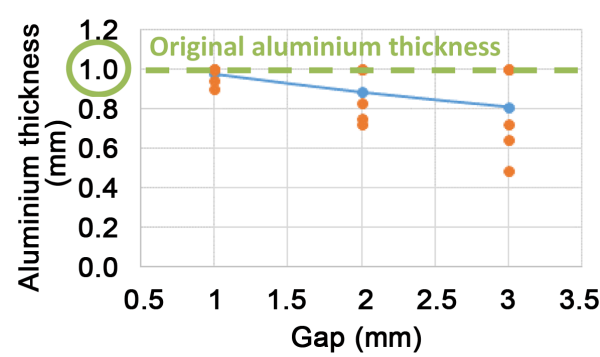

(a)

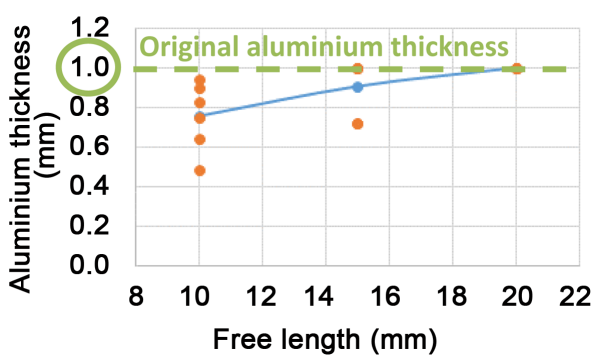

(b)

Figure 11. Aluminium sheet thickness as a function of (a) initial gap between aluminium flyer and copper target sheet, (b) free length.

examined. Based on that analysis, the main parameters affecting the weld characteristics and their general trends were identified (blue line in Figure 11 and following). Afterwards, this same data was analysed by means of a Pareto analysis and predicted response graphs for the transferable force and the dimensions of the weld seam.

Main parameters affecting the aluminium sheet thickness reduction near the welded zone

Figure 11(a) shows that the lowest initial gap of $1 \mathrm{~mm}$ most likely resulted in the smallest reduction of the aluminium sheet thickness, whereas Figure 11(b) shows that the highest free length of $20 \mathrm{~mm}$ always resulted in no reduced aluminium sheet thickness. Contrary, a combination of the highest initial gap of $3 \mathrm{~mm}$ and the lowest free length of $10 \mathrm{~mm}$, resulted in the highest sheet thickness reduction of $0.5 \mathrm{~mm}$ (specimen no. 11) and $0.6 \mathrm{~mm}$ (specimen no. 17).

A strong interaction was suspected between these 2 parameters, which can be explained geometrically. For the lowest value of the free length of $10 \mathrm{~mm}$, only an aluminium sheet length of 2 or $4 \mathrm{~mm}$ (depending on the overlap distance) remains that was not covered by the coil conductor. This small aluminium flyer sheet length should bend towards the copper target sheet over an initial gap distance of $3 \mathrm{~mm}$ in a time period of $\mu$ s. Therefore, this parameter combination resulted in the largest reduction of the aluminium sheet thickness. The original aluminium sheet thickness of $1 \mathrm{~mm}$ was most likely retained for the lowest initial gap of $1 \mathrm{~mm}$ and the highest free length of 20 $\mathrm{mm}$.

\section{Main parameters affecting the maximum transferable force}

A similar trend as observed for the aluminium sheet thickness has been identified for the effect of the welding parameters on the transferable force. Figure 12(a) and Figure 12(b) show that for the lowest initial gap of $1 \mathrm{~mm}$ and the highest free length of $20 \mathrm{~mm}$, the highest transferable forces were obtained. At these particular parameter values, also no aluminium thickness reduction was observed, as illustrated in Figure 11.

Therefore, the transferable force was investigated as a function of the aluminium sheet thickness (see Figure 13). This showed that a linear correlation existed between the aluminium sheet thickness near the welded zone after welding and the maximum transferable force. Indeed, a reduction in the aluminium sheet thickness resulted in a lower transferable force. The aluminium sheet thickness can also be related to the 


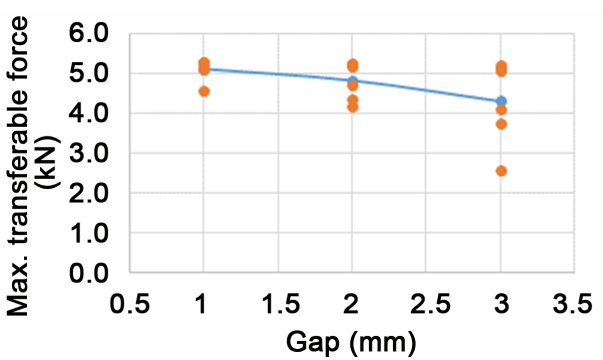

(a)

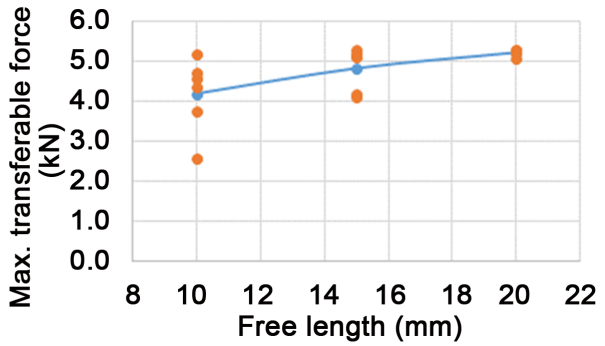

(b)

Figure 12. Maximum transferable force as a function of (a) initial gap between aluminium flyer and copper target sheet, (b) free length.

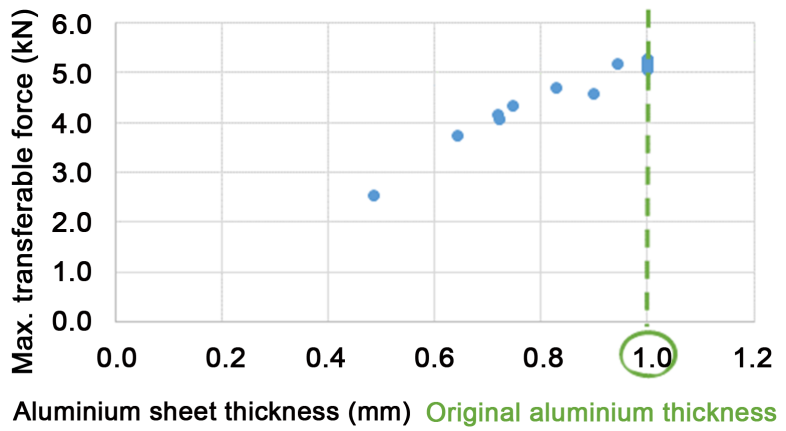

Figure 13. Maximum transferable force of the hybrid sheet weld as a function of the aluminium sheet thickness

failure mode during lap shear testing. This is because welds with a large aluminium sheet thickness reduction of $20 \%$ or more, tended to fail in the aluminium base material due to necking (see Table 4).

No effect of the capacitor charging energy or the overlap distance on the transferable force was identified for the regarded experiments. A Pareto analysis confirmed that the gap and the free length were the 2 dominating parameters affecting the transferable force (see Figure 14).

\section{Main parameters affecting the weld length}

An increasing weld length was mainly noticed at a smaller gap of $1 \mathrm{~mm}$ (see Figure 15). A Pareto analysis also showed that gap is the dominating parameter affecting the weld length, while all other considered parameters were less important with regard to this effect (see Figure 16).

\section{Main parameters affecting the weld width}

The capacitor charging energy and gap were the main parameters causing variation of the total weld width (see Figure 17). A larger capacitor charging energy up to $7.5 \mathrm{~kJ}$ resulted in a longer total weld width and a lower variation thereof. Regarding the initial gap, an optimum value was observed within the selected outer parameter boundaries, which is likely to be situated between 2 and $2.5 \mathrm{~mm}$.

A Pareto analysis confirmed that the capacitor charging energy and the gap were the dominating parameters affecting the weld length (see Figure 18). 


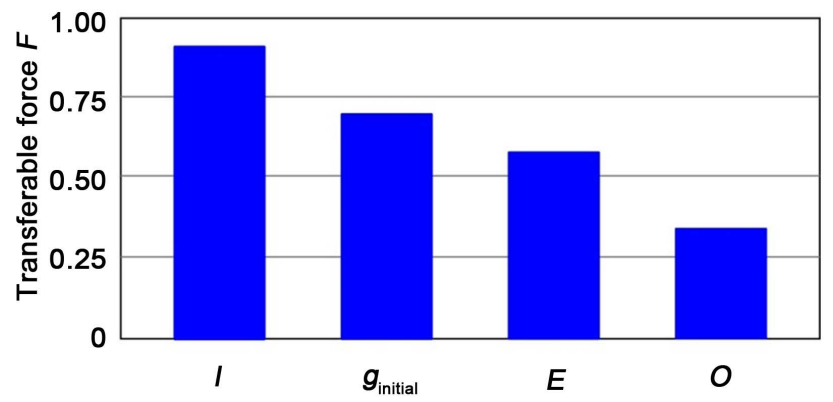

Figure 14. Pareto effects for the transferable force $\mathrm{F}$ determined during lap shear testing on welding of EN AW-1050 flyers to Cu-DHP 240 targets ( 1 = overlap length; $g_{\text {initial }}=$ gap; $\mathrm{E}=$ Energy; $\mathrm{O}=$ Overlap).

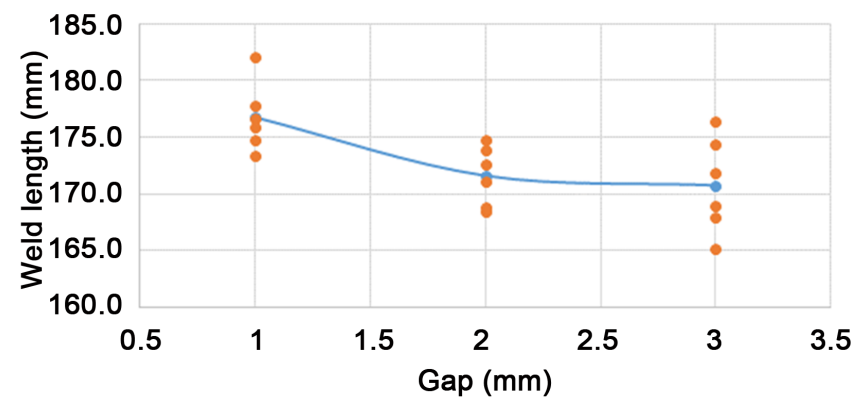

Figure 15. Weld length as a function of the initial gap between the aluminium flyer and copper target sheet.

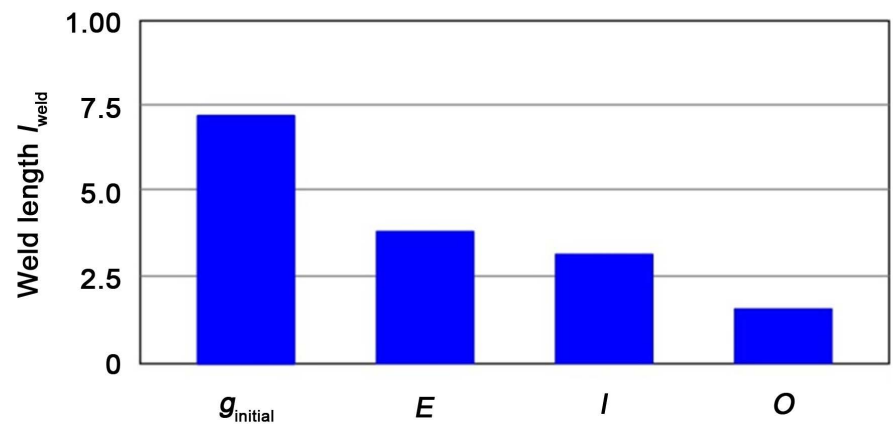

Figure 16. Pareto effects for the weld length, obtained by welding of EN AW-1050 flyers to CuDHP 240 targets $\left(g_{\text {initial }}=\right.$ gap; $\mathrm{E}=$ Energy; 1 = overlap length; $\mathrm{O}=$ Overlap).

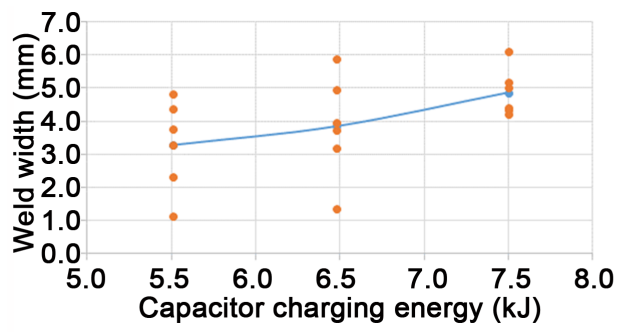

(a)

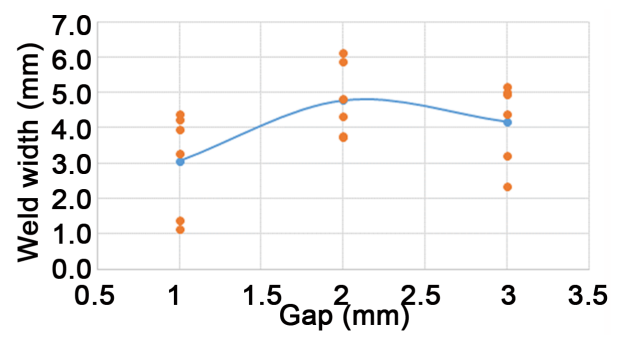

(b)

Figure 17. Weld width as a function of (a) capacitor charging energy, (b) initial gap between aluminium flyer and copper target sheet. 


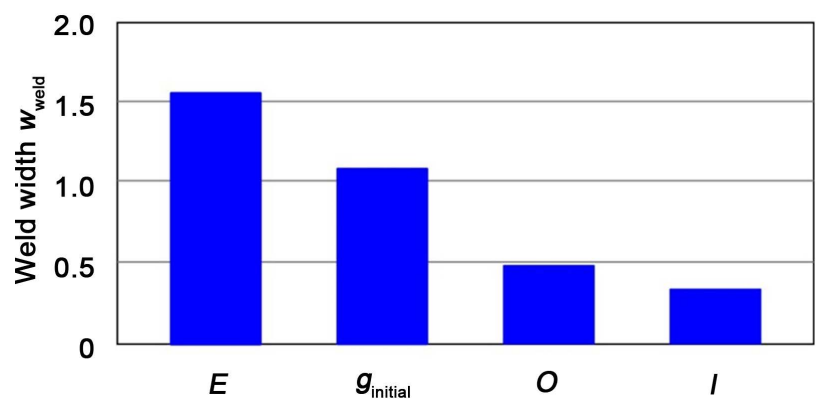

Figure 18. Effects Pareto for the weld width, obtained by welding of EN AW-1050 flyers to CuDHP 240 targets ( $\mathrm{E}=$ Energy; $\mathrm{g}_{\text {initial }}=$ gap; $\mathrm{O}=$ Overlap; 1 = overlap length).

More detailed insight in the dominating effects of the welding parameters was given via the predicted response graphs. These graphs show for each of the influencing parameters how it affects the weld characteristics, assuming that all other parameters are fixed to the pre-selected values. In particular, the predicted response graphs in Figure 19 show the transferable force, the weld width and weld length as a function of the capacitor charging energy, overlap, gap and free length. This means that the graph in the upper left corner shows the effect of the capacitor charging energy on the transferable force if the overlap is fixed at $8 \mathrm{~mm}$, the gap at $2 \mathrm{~mm}$ and the overlap at $14 \mathrm{~mm}$. Predicted response graphs can be generated for any set of pre-selected values within the parameter range considered in the study with the help of the Cornerstone software [35]. For other combinations of pre-selected values, the height and the slope of the curves can vary, but the general trends, described in the following, usually are similar.

The predicted response graphs confirm the same trend of the effect of the capacitor charging energy, overlap, initial gap and free length on the weld characteristics, as observed for the individual results plotted in Figure 12, Figure 15 and Figure 17. The most effective way to increase the transferable force is to lower the initial gap and to increase the free length, since both parameters also resulted in a smaller aluminium sheet thickness reduction near the welded zone. The transferable force was not significantly and unambiguously influenced by the capacitor charging energy. An increase in weld width was mainly achieved for an increase in capacitor charging energy and initial gap, whereas an increase in weld length was obtained for a decrease in initial gap. In general for all 3 weld characteristics, the initial gap is one of the most influential parameters, since this distance between flyer and target sheet is one of the factors that determined the impact angle and impact velocity.

Furthermore, an increase in weld width did not necessarily result in an increase in the transferable force. A hybrid sheet with narrow weld width, but without remarkable thinning of the aluminium, could therefore have a higher quality compared to one with long weld width but severe pre-damage in the aluminium. However, no unambiguous relation between the weld width and the transferable force was identified in these test series. This can be attributed to the aluminium sheet thickness reduction, which is the dominant parameter affecting the transferable force attained (see Figure 13). The original aluminium sheet thickness should therefore be maintained after the welding 


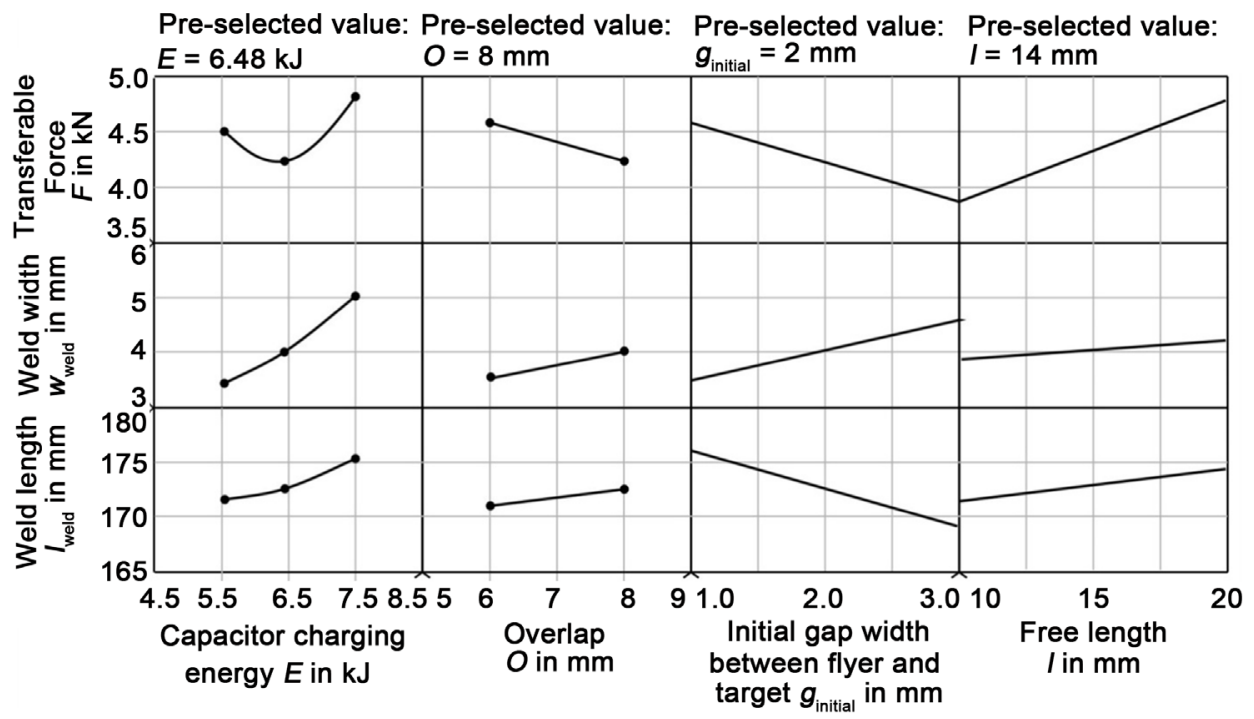

Figure 19. Predicted response graphs for the transferable force $\mathrm{F}$, the width of the weld $\mathrm{w}_{\text {weld }}$ and

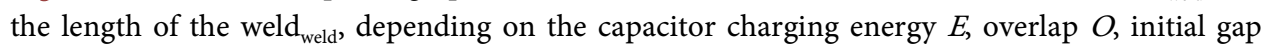
between flyer and target $g_{\text {initial }}$ and free length $l$.

operation, in order to eliminate the effect of thickness reduction on the transferable force.

\subsection{Modified Experimental Set-Up with a Rounded Spacer}

Based on the results obtained by the Taguchi L18 design, 3 specimens showed a large reduction (from $30 \%$ up to 50\%) of the aluminium sheet thickness near the welded zone after welding. It was proven that this was attributed to the sharp edge of the right spacer in combination with the specific parameters considered. This aluminium sheet thickness reduction in the welded zone significantly lowered the maximum transferable force attained. Hence, these particular parameter combinations were repeated using a rounded spacer. The modified experimental set-up showing a rounded spacer with a radius of $1.5 \mathrm{~mm}$ is illustrated in Figure 3.

All specimens with a rounded spacer displayed no visual reduction of the sheet thickness, which was beneficial for the joint quality and in particular the transferable force. However, when the sheet thickness was measured by optical microscopy, a small thickness reduction of $10 \%$ was still present compared to the original sheet thickness of $1 \mathrm{~mm}$. This small reduction was probably caused by elongation of the sheet material during the welding operation. Figure 20 shows a comparison between the aluminium sheet thickness reduction obtained with a straight, sharp-edged spacer and a rounded spacer, for the same parameter combination. Here, the effect of the spacer on the aluminium sheet thickness reduction is clearly illustrated. Furthermore, no correlation with the capacitor charging energy selected was identified, since all aluminium sheet thickness values obtained with a rounded spacer were similar for the different energies.

The transferable force for hybrid sheet welds produced with a straight, sharp-edged spacer and with a rounded spacer is compared in Table 5. Although an increase in the 
Table 5. Comparison of the aluminium sheet thickness and transferable force for welds produced with a straight, sharp-edged spacer and a rounded spacer, for the same parameter combinations.

\begin{tabular}{ccccc}
\hline & Hybrid sheet welds obtained with a straight, sharp-edged spacer & \multicolumn{2}{c}{ Hybrid sheet welds obtained with a rounded spacer } \\
\cline { 2 - 5 } Specimen no. & $\begin{array}{c}\text { Aluminium sheet } \\
\text { thickness after } \\
\text { welding [mm] }\end{array}$ & $\begin{array}{c}\text { Average maximum } \\
\text { transferable force of 3 lap } \\
\text { shear specimens [kN] }\end{array}$ & $\begin{array}{c}\text { Aluminium sheet } \\
\text { thickness after } \\
\text { welding [mm] }\end{array}$ & $\begin{array}{c}\text { Average maximum } \\
\text { transferable force of } \\
3 \text { lap shear specimens [kN] }\end{array}$ \\
\hline 11 & 0.5 & 2.6 & 0.9 & 0.9 \\
17 & 0.6 & 3.8 & 0.9 & 4.3 \\
5
\end{tabular}
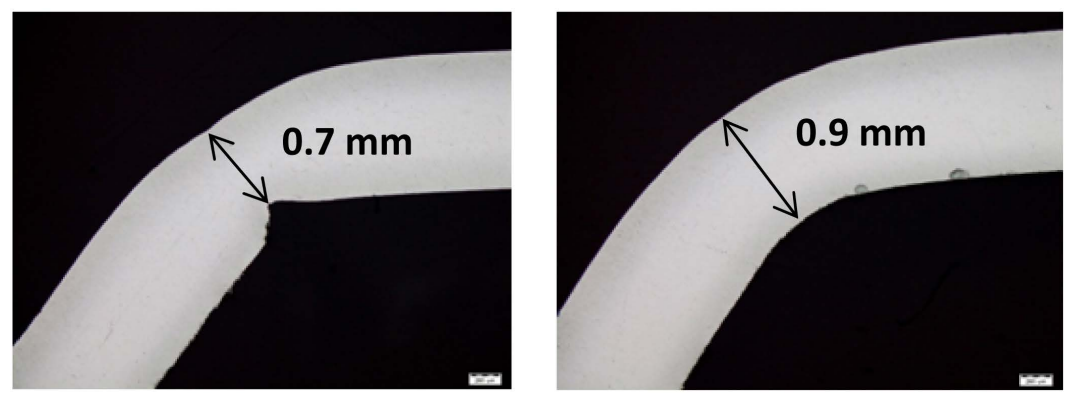

Figure 20. Effect of using a (a) straight, sharp-edged spacer, (b) rounded spacer on the aluminium sheet thickness near the welded zone (specimen no. 5) (original aluminium sheet thickness $=1 \mathrm{~mm})$.

maximum transferable force is noticeable, the highest transferable force (up to $5.3 \mathrm{kN}$ ) which was obtained for welds without a sheet thickness reduction (see Table 4), was not achieved. It is likely that a modification of the radius of the rounded spacer may increase the transferable force even further. However, it would be more convenient to increase the free length to $20 \mathrm{~mm}$ or decrease the initial gap to $1 \mathrm{~mm}$ if a higher transferable force is desired, as shown in the predicted response graphs in Figure 19.

The use of a rounded spacer in producing the hybrid sheet weld therefore had a beneficial effect. An increase of $28 \%-80 \%$ in the aluminium sheet thickness and an increase of $13 \%-77 \%$ in the transferable force was achieved, compared to the use of the straight spacer (see Table 5). However, it has to be considered that by using a fillet radius on the spacer, the welds no longer had an effective free length of $10 \mathrm{~mm}$. It would therefore be more correct to report a corrected free length, e.g. $11.5 \mathrm{~mm}$ instead of 10 $\mathrm{mm}$.

\section{Conclusions}

Aluminium-copper sheets were joined by means of the electromagnetic pulse technology using different parameter combinations, selected according to a Taguchi L18 design. The weld shape, interfacial morphology, transferable force, failure modes and dimensions of the weld seam were examined in detail. Subsequently, these structural and mechanical characteristics were related to the welding parameters, namely the capacitor charging energy, the initial gap, the overlap distance and the free length. A Pareto 
analysis allowed identifying the most influential welding parameters. The trends between these dominating parameters and the weld characteristics were determined using predicted response graphs. A modification to the experimental set-up configuration consisted of using a rounded spacer instead of a straight, sharp-edged spacer. This was done to avoid aluminium sheet thickness reduction near the welded zone. The following conclusions can be drawn from the present experimental study.

Hybrid sheet welds were successfully obtained for all parameters conditions considered. An indent shape located at the extremities of the weld was attributed to the change of the current direction at the end of the coil conductor, resulting in a current concentration at the sheet extremities. The centre of the hybrid sheet welds evolved from a non-welded zone to a welded zone. Based on measurements and modelling studies found in literature, this can be explained by the evolution in the direction and magnitude of the Lorentz forces, which determine the impact angle and velocity during the welding process. Under the correct welding conditions, a jet occurred that removed the oxide layers and hence established a metallurgical bond. The welded zone started with a wavy interface with interfacial layers and evolved to a relatively flat interface without interfacial layers.

The absolute values of the maximum transferable force during lap shear testing ranged from 2.6 to $5.3 \mathrm{kN}$. Accordingly, the transferable force/specimen width during lap shear testing ranged from 57.8 to $115.6 \mathrm{~N} / \mathrm{mm}$ for a lap shear specimen width of 45 $\mathrm{mm}$. The maximum transferable force depended on the minimum specimen thickness and the strength of the hybrid sheet weld. For no aluminium sheet thickness reduction, the maximum transferable force was determined by the hybrid sheet weld strength and failure occurred in the base material. Hence, high quality joints were obtained for no aluminium sheet thickness reduction and for a sheet weld strength which was at least as high as that of the base material. For small aluminium sheet thickness reductions (approximately $10 \%$ ), and for a sheet strength slightly lower compared to that of the base material, failure occurred in the joint. At large aluminium sheet thickness reduction of $20 \%$ or more, the maximum transferable force was linearly correlated to the aluminium sheet thickness and hence failure occurred in the base material. In this case, a reduced aluminium sheet thickness resulted in a lower maximum transferable force.

The most effective way to increase the transferable force was to lower the initial gap to $1 \mathrm{~mm}$ and to increase the free length to $20 \mathrm{~mm}$, since both parameters resulted in no aluminium sheet thickness reduction near the welded zone. Alternatively, the use of a rounded spacer to produce the hybrid sheet welds resulted in a higher transferable force and a smaller aluminium sheet thickness reduction, compared to hybrid sheet welds produced with a straight, sharp-edged spacer. Therefore, this modified experimental set-up allowed to decrease the effect of the aluminium sheet thickness reduction on the transferable force achieved. The weld width obtained ranged from 1 to $6 \mathrm{~mm}$ and an increase was mainly achieved for an increase in capacitor charging energy and initial gap. However, an increase in weld width did not necessarily result in an increase in the transferable force. A narrow weld width could therefore have higher joint quality. The 
weld lengths obtained ranged from 165 to $182 \mathrm{~mm}$ and an increase was noticed for a decrease in the initial gap.

\section{Acknowledgements}

This project has received funding from the European Union's Horizon 2020 research and innovation programme under grant agreement No. H2020-FoF-2014-677660JOIN-EM.

\section{References}

[1] Lysenko, D.N., Ermolaev, V.V. and Dudin, A.A. (1970) Method of Pressure Welding. USPatent No. 3520049.

[2] Harvey, G.W. and Brower, D.F. (1958) Metal Forming Device and Method. US-Patent No. 2976907.

[3] Acarer, M. (2012) Electrical, Corrosion, and Mechanical Properties of Aluminium-Copper Joints Produced by Explosive Welding. Journal of Materials Engineering and Performance, 21, 2375-2379. http://dx.doi.org/10.1007/s11665-012-0203-6

[4] Pysk, V., Risch, D., Kinsey, B.L., Tekkaya, A.E. and Kleiner, M. (2011) Electromagnetic Forming-A Review. Journal of Materials Processing Technology, 211, 787-829. http://dx.doi.org/10.1016/j.jmatprotec.2010.12.012

[5] Kapil, A. and Sharma, A. (2015) Magnetic Pulse Welding: An Efficient and Environmentally friendly Multi-Material Joining Technique. Journal of Cleaner Production, 100, 35-58. http://dx.doi.org/10.1016/j.jclepro.2015.03.042

[6] Shribman, V. and Tomer, Y. (2006) Magnetic Pulse Technology for Improved Tube Joining and Forming. Tube \& Pipe Technology, 91-95.

[7] Hisashi, S., Isao, S., Sherif, R. and Hidekazu, M. (2009) Numerical Study of Joining Process in Magnetic Pressure Seam Welding. Transactions of JWRI, 38, 63-68.

[8] Uhlmann, E. and Ziefle, A. (2010) Modelling Pulse Magnetic Welding Processes-An Empirical Approach. Proceedings of the 4th International Conference on High Speed Forming (ICHSF 2010), Columbus, 9-10 March 2010, 108-126.

[9] Kore, S.D., Imbert, J., Worswick, M.J. and Zhou, Y. (2009) Electromagnetic Impact Welding of Mg to $\mathrm{Al}$ Sheets. Science and Technology of Welding and Joining, 14, 549-553. http://dx.doi.org/10.1179/136217109X449201

[10] Okagawa, K. and Aizawa, T. (2004) Impact Seam Welding with Magnetic Pressure for Aluminum Sheets. Material Science Forum, 465-466, 231-236. http://dx.doi.org/10.4028/www.scientific.net/MSF.465-466.231

[11] Göbel, G., Kaspar, J., Herrmanssdörfer, T., Brenner, B. and Beyer, E. (2010) Insights into Intermetallic Phases on Pulse Welded Dissimilar Metal Joints. Proceedings of the 4th International Conference on High Speed Forming (ICHSF 2010), Columbus, 9-10 March 2010, 127-136.

[12] Psyk, V., et al. (2008) Process Analysis and Physical Simulation of Electromagnetic Joining of Thin-Walled Parts. Proceedings of the 3rd International Conference on High Speed Forming (ICHSF), Dortmund, 10-11 March 2008, 181-190.

[13] Daube, J., Götsch, A. and Hänisch, H. (1966) Ausnutzung Gespeicherter Elektrischer Energie zur Magnetumformung von Metallen und Grenzen dieses Verfahrens. Fertigungstechnik und Betrieb, 16, 107-113. 
[14] Belyy, I.V., Fertik S.M. and Khimenko L.T. (1977) Spravochnik po magnitno-impul' snoy obrabotke metallov [Electromagnetic Metal Forming Handbook]. English Translation by Altynova M. M. Material Science and Engineering Department, Ohio State University, 1996.

[15] Bertholdi, W. and Daube, J. (1966) Die elektrohydraulische und die elektromagnetische Umformung von Metallen. Urania. Gesellschaft zur Verbreitung wissenschaftlicher Kenntnisse.

[16] Erdösi, J. and Meinel, M. (1984) Elektrische Hochgeschwindigkeitsbearbeitung. Fertigungstechnik und Betrieb, 34, 600-601.

[17] Bergmann, J.P., Petzoldt, F., Schürer R. and Schneider, S. (2013) Solid-State Welding of Aluminium to Copper-Case Studies. Welding in the World, 57, 541-550.

http://dx.doi.org/10.1007/s40194-013-0049-z

[18] Abbasi, M., Karimi Taheri, A. and Salehi, M.T. (2001) Growth Rate of Intermetallic Compounds in $\mathrm{Al} / \mathrm{Cu}$ Bimetal Produced by Cold Roll Welding Process. Journal of Alloys and Compounds, 319, 233-241. http://dx.doi.org/10.1016/S0925-8388(01)00872-6

[19] Marya, M., Marya, S. and Priem, D. (2004) On the Characteristics of Electromagnetic Welds between Aluminium and Other Metals and Alloys. 57 th annual Assembly of the International Institute of Welding, Osaka, 11-16 July 2004, 1-12

[20] Raoelison, R.N., Racine, D., Zhang, Z., Buiron, N., Marceau, D. and Rachik, M. (2014) Magnetic Pulse Welding: Interface of $\mathrm{Al} / \mathrm{Cu}$ Joint and Investigation of Intermetallic Formation Effect on the Weld Features. Journal of Manufacturing Processes, 16, 427-434. http://dx.doi.org/10.1016/j.jmapro.2014.05.002

[21] Stern, A., Shribman, V., Ben-Artzy, A. and Aizenshtein, M. (2014) Interface Phenomena and Bonding Mechanism in Magnetic Pulse Welding. Journal of Materials Engineering and Performance, 23, 3449-3458. http://dx.doi.org/10.1007/s11665-014-1143-0

[22] Zhang Y., et al. (2011) Application of High Velocity Impact Welding at Varied Different Length Scales. Journal of Materials Processing and Technology, 21, 944-985. http://dx.doi.org/10.1016/j.jmatprotec.2010.01.001

[23] Zhang, Y. (2010) Investigation of Magnetic Pulse Welding on Lap Joint of Similar and Dissimilar Materials. PhD Thesis, The Ohio State University, Columbus.

[24] Schäfer, R. and Pasquale, P. (2011) Material Hybrid Joining of Sheet Metals by Electromagnetic Pulse Technology. Key Engineering Materials, 473, 61-68.

http://www.pstproducts.com/EMPT_sheetwelding_PSTproducts.pdf http://dx.doi.org/10.4028/www.scientific.net/KEM.473.61

[25] Kore, S.D., Date, P.P. and Kulkarni, S.V. (2007) Effect of Process Parameters on Electromagnetic Impact Welding of Aluminium Sheets. International Journal of Impact Engineering, 34, 1327-1341. http://dx.doi.org/10.1016/j.ijimpeng.2006.08.006

[26] Kore, S.D., et al. (2010) Electromagnetic Pulse Welding of Copper-to-Copper Sheets. International Journal of Material Forming, 3, 117-121. http://dx.doi.org/10.1007/s12289-009-0661-z

[27] Standard (2013) NBN EN 485-2: 2013 Aluminium and Aluminium Alloys. Sheet, Strip and Plate-Part 2: Mechanical Properties.

[28] Standard (1997) DIN EN 1652: 1997 Copper and Copper Alloys. Plate, Sheet, Strip and circlEs for General Purposes.

[29] Poynting GmbH. Dortmund, Germany. http://www.poynting.de/en/

[30] Göbel, G., Beyer, E., Kaspar, J. and Brenner, B. (2012) Dissimilar Metal Joining: Macro- and Microscopic Effects of MPW. Proceedings of the 5 th International Conference on High Speed Forming (ICHSF 2012), Dortmund, 24-26 April 2012, 179-188. 
[31] Bühler, H. and Bauer, D. (1968) Ein Beitrag zur Magnetumformung rohrförmiger Werkstücke. Werkstatt und Betrieb, 110, 513-516.

[32] Watanabe, M. and Kumai, S. (2009) High-Speed Deformation and Collision Behavior of Pure Aluminium Plates in Magnetic Pulse Welding. Materials Transactions, 50, 2035-2042. http://dx.doi.org/10.2320/matertrans.L-M2009816

[33] Doley, J.K. and Kore S.D. (2011) Study of Impact Behavior of Sheets in Electromagnetic Pulse Welding. Proceedings of the 64th Annual Assembly of the International Institute of Welding, CD-ROM Edition, Chennai, 17-22 July 2011, 889-892.

[34] Cuq-Lelandais, J.-P., et al. (2016) 3D Impacts Modeling of the Magnetic Pulse Welding Process and Comparison to Experimental Data. Proceedings of the 7 th International Conference on High Speed Forming (ICHSF 2016), Dortmund, 27-28 April 2016, 13-23.

[35] Cornerstone Software. http://www.camline.com/en/products/cornerstone.html

\section{Submit or recommend next manuscript to SCIRP and we will provide best service} for you:

Accepting pre-submission inquiries through Email, Facebook, LinkedIn, Twitter, etc. A wide selection of journals (inclusive of 9 subjects, more than 200 journals)

Providing 24-hour high-quality service

User-friendly online submission system

Fair and swift peer-review system

Efficient typesetting and proofreading procedure

Display of the result of downloads and visits, as well as the number of cited articles

Maximum dissemination of your research work

Submit your manuscript at: http://papersubmission.scirp.org/

Or contact wjet@scirp.org 